\title{
O TRABALHO DA ENFERMEIRA NA UNIDADE DE HEMODIALISE
}

\author{
Maria Ignez Ribeiro de Oliveira Ciconelli * \\ Lia Hoelz Alvares *
}

\section{I — INTRODUÇÃO}

Foi introduzido, nos últimos anos, uma nova área no campo da enfermagem: o cuidado ao paciente em hemodiálise.

São indicações da hemodiálise: a insuficiência renal aguda, as intoxicações exógenas por venenos dialisáveis, e a insuficiência renal crônica (RIO6). A última leva um grande número de pacientes a viverem na dependência de uma máquina, o hemodialisador.

Procurar-se-á, neste trabalho, focalizar alguns aspectos fundamentais da hemodiálise, os problemas apresentados pelos pacientes renais crônicos, e a atuação da enfermeira na unidade de hemodiálise.

\section{II - HISTÓRICO}

Os fundamentos da hemodiálise foram estabelecidos por Abel, Rowntree e Turner, em 1913, em um trabalho que relata o seguinte: "realizou-se um método mediante o qual o sangue de um animal vivo pode ser submetido à diálise fora do corpo, e voltar de novo à circulação normal" (HAMPERS \& SCHUPAK4). Uma grande linha experimental existe entre este primeiro trabalho, e o primeiro hemodialisador de aplicação prática, construído, na Holanda, por Kolff, em 1941 (RIO5).

Partindo-se do modelo Kolff, os dialisadores foram sendo aperfeiçoados, existindo, atualmente, três tipos fundamentais:

- o rim de bobinas, composto por uma tubulação de celofane, enrolada, em forma de espiral, em torno de um núcleo central tipo Kolff (atualmente, o "Twin-Coil" Travenol);

- o rim em placas, de fluxo paralelo, composto por 3 placas de

* Professor Colaborador do Departamento de Enfermagem Geral e Especializada da Escola de Enfermagem de Ribeirão Preto, USP. 
acrflico transparentes, entre as quais se coloca duas folhas de celofane (membranas), tipo Kill; capilares.

- o rim capilar composto por um feixe de numerosos e finos

\section{III - ASPECTOS FUNDAMENTAIS DA HEMODIÁLISE}

A hemodiálise é, essencialmente, um meio de remover as escórias do sangue, e suprí-lo de substnâcias necessárias a ele, função esta desempenhada pelos rins em circunstâncias normais. O principio que rege a hemodiálise consiste na permeabilidade da membrana, na qual ocorre a difusão (FELLOWS2). Esta é conseqüência da tendência ao equilíbrio, nos sistemas em que existe um gradiente de concentração (colocando-se em contacto duas soluções de concentração diferentes, separadas por uma membrana semi-permeável, depois de algum tempo observa-se que suas concentrações são iguais, devido à passagem de substâncias da solução mais concentrada para a menos concentrada) (RIO5). O hemodialisador é o aparelho que permite esta difusão.

No hemodialisador, ocorre troca de pequenas moléculas entre o sangue conduzido para fora do organismo através uma canulação de vasos (num sistema de circulação extra-corpórea), e um líquido de concentração adequada (o líquido de diálise). Estas trocas se realizam através de uma membrana semi-permeável, que separa o líquido de diálise do sangue, o qual regressa depurado ao organismo.

A membrana semi-permeável usada nos hemodialisadores pode ser definida como uma lâmina delgada, maleável, flexível, de origem sobretudo animal ou vegetal. A mais usada é a de celofane, cujos poros têm, aproximadamente, 2,4 milimicrons de raio. Esta membrana não permite a passagem de proteínas plasmáticas para o banho de diálise, nem a passagem de bactérias deste para o sangue (HAMPERS \& SCHUPAK4).

Tem-se usado, modernamente, o Cuprophane no lugar do celofane, pois a membrana de Cuprophane apresenta a vantagem de uma maior dialisância por unidade de superfície.

\section{Acesso à corrente circulatória: cânula e fístula}

O acesso à corrente circulatória constituiu um fator que dificultou, durante muito tempo, o uso, de hemodiálises repetidas. Em 1960, Quinton, Dillard e Scribner idealizaram um processo de "shunt" artério-venoso, conhecido como Cânula de Scribner (anexo I). Em 1966, Brescia-Cimino propuseram o uso da fístula artério-venosa interna, método de grande aceitação atual (FERRE'). 
Esses métodos vieram a permitir diálises periódicas em pacientes renais crônicos, sem necessidade de sucessivos cateterismos das artérias e veias.

A Cânula de Scribner consiste em 2 pequenas cânulas de Teflon, de calibre variável, e em duas tubulações de Silastic, firmemente unidas às duas cânulas. Insere-se as cânulas de Teflon na artéria e veia superficiais, ficando as tubulações de Silastic parcialmente exteriozadas, e unidas por um intermediário de Teflon. Este conjunto forma, então, uma ponte artério-venosa.

Para realizar a hemodiálise, liga-se o doente ao aparelho ao nível do intermediário de Teflon (FERRE 3 ).

A fístula artério-venosa consiste na anastomose, subcutânea da artéria radial e a veia correspondente, empregando posteriormente, a veia dilatada do antebraço (sangue arterializado), para a hemodiálise (HAMPERS \& SCHUPAK4).

As fístulas artério-venosas, apesar de obrigarem a venopunturas freqüentes, são preferidas pelos pacientes que têm experiências com os dois métodos. Essas fístulas são de maior duração, e apresentam menor índice de complicações.

O procedimento correto para manipulação da cânula de Scribner e da fístula artério-venosa encontra-se no anexo II.

\section{O líquido de diálise}

O líquido de diálise consiste em aquelas substâncias que são normalmente encontradas no sangue do paciente, e que não podem ser removidas, tal como o magnésio, e em aquelas substâncias que podem ser fornecidas ao paciente, como o bicarbonato. As substâncias que precisam ser removidas (tal como a uréia) não são colocadas no líquido de diálise (FELLOWS2).

No serviço de hemodiálise do Hospital das Clínicas da Faculdade de Medicina de Ribeirão Preto, a composição "standard" do banho de diálise é a seguinte:

\begin{tabular}{lrrlrr} 
Sódio & 135 & $\mathrm{mEq} / 1$ & Cálcio & $2,5 \mathrm{mEq} / 1$ \\
Potássio & $2,6 \mathrm{mEq} / 1$ & Cloro & 104 & $\mathrm{mEq} / 1$ \\
Magnésio & $1,5 \mathrm{mEq} / 1$ & Bicarbonato & 36 & $\mathrm{mEq} / 1$ \\
& & & Glicose & \multicolumn{2}{c}{ variável }
\end{tabular}

A composição "standard" do líquido de diálise pode sofrer modificações, na dependência das condições e necessidades de cada paciente.

Obtém-se uma solução de composição igual à indicada anteriormente, diluindo as gramas correspondentes aos $\mathrm{mEq} / 1$ de sais necessários, em 100 litros de água de torneira. 
Existem, ainda, outras maneiras de se obter o líquido de diálise, tais como os preparados comerciais que contém os sais em solução concentrada.

Nos tanques dos hemodialisadores, existem, geralmente, dispositivos que misturam os sais com água, garantindo a homogeneidade do líquido de diálise.

Segundo SABBAGA e VASCONCELOS,(6) os cuidados com o líquido de diálise são os seguintes:

- o banho de diálise deve ser preparado imediatamente antes de seu uso, a fim de se evitar a proliferação bacteriana no banho;

- a temperatura do líquido de diálise, para entrar em contacto com a membrana dialisadora, deve estar entre $38 .^{\circ}$ a $40 .^{\circ} \mathrm{C}$;

- o pH do banho deve ser verificado após seu preparo, e deve ser ajustado em torno de 7,4;

- a água de torneira usada para o preparo do banho necessita ser analisada, para se evitar teores elevado de sais minerais, tais como Cálcio, Magnésio, Ferro, etc...

- a proliferação bacteriana no banho pode ser prevenida de várias maneiras: esfriamento do banho do reservatório à temperatura de $20^{\circ} \mathrm{C}$, aquecendo-se somente o líquido que vai entrar em contacto com a membrana; uso do banho de diálise sem glicose (não recomendado, pois a ausência de glicose diminue a osmolaridade dc banho); exposição do banho a um foco de luz ultra-violeta (eficiência discutida); colocação de antissépticos no reservatório do rim artificial, nos intervalos entre as hemodiálises.

\section{Tipos de circulação do líquido de diálise}

Existem dois sistemas diferentes de circulação do líquido de díalise: o sistema de recirculação, e o sistema tipo "single-pass".

No sistema de recirculação, o líquido de diálise é retirado do reservatório, ou tanque, através de uma bomba, é colocado em contacto com a membrana, e é devolvido ao reservatório. Este ciclo se repete permanentemente. $O$ banho vai, então, progressivamente, se saturando, sendo necessário sua troca periódica, a intervalos regulares, a fim de manter a eficácia do mesmo. Ex.: - o primeiro modelo Kolff "Twin-Coil".

No sistema tipo "single-pass", uma bomba retira, continuamente, uma certa quantidade de líquido do reservatório, e joga-o na unidade dialisadora. Após entrar em contacto com a membrana, o líquido é desprezado, não voltando mais ao reservatório. Ex.: - rim artificial Kill. 
O modelo mais moderno de "Twin-Coil" associa características dos dois sistemas, sendo por isto chamado de R.S.P. (recirculating Single-pass). A recirculação do banho é apenas parcial. A unidade dialisadora, o "Coil", é colocada num compartimento que suporta um volume de 8 litros,compartimento este separado do tamque do líquido de diálise. Uma bomba retira, continuamente um certo volume de líquido do tanque, e joga-o no compartimento de recirculação (canister). Este volume varia de 300 a $500 \mathrm{ml}$ de líquido por minuto. Isto produz um excesso de volume líquido nocanister, que é drenado, e desprezado através de um sifão. O líquido que vem do tanque garante uma constante e permanente renovação do líquido contido no compartimento de recirculação (SABBAGA \& VASCONCELOS6).

\section{Heparinização}

Durante todo o tempo em que o paciente se submete à hemodiálise há necessidade de seu sangue ser heparinizado, por se tratar de um sistema de circulação extra-corpórea.

A heparinização deve ser feita imediatamente antes da instalação da hemodiálise, na dosagem de 1.5 a $2 \mathrm{mg} / \mathrm{Kg}$ de pêso do paciente.

Dois métodos podem ser usados para heparinização: sistêmico ou regional. Este último é particularmente indicado em casos de pacientes com tendência hemorrágica, cirurgia recente de grande vulto, e traumas com superfície cruentas propícias a sangramento (SABBAGA \& VASCONCELOS6).

No método sistêmico, o anticoagulante é injetado, antes do início da diálise, por via endovenosa, sendo a heparinização mantida através da introdução do anticoagulante no "set" arterial a cada duas horas.

No método regional, o anticoagulante é administrado através do "set" arterial, tornando incoagulável somente o sangue que circula no aparelho. Quando o sangue deixa o dialisador, e retorna ao paciente, nele é lançado protamina (na proporção $1,5 \mathrm{mg}$ de protamina para cada $\mathrm{mg}$ de heparina), o que restabelece a coagulabilidade do sangue antes deste voltar ao paciente.

O tempo de coagulação, durante a diálise, deve sempre ser mantido superior a 20 minutos.

Tipos de dialisadores: vantagens e desvantagens

Os modelos de hemodialisadores mais usados entre nós são:

- o modelo "Twin-Coil" R.S.P.

- o modelo Kill 
Segundo SABBAGA e VASCONCELOS,(6) as vantagens e desvantagens destes modelos são as seguintes:

"Twin-Coil", vantagens: - alta dialisância (o dobro do modelo Kill). As diálises duram em média de 4 a 6 horas; - alta ultrafiltração, com taxa maior de perda de líquido por unidade de tempo que a do Kill; - facilidade e rapidez na montagem do aparelho; - existência de uma bomba rotatória no "set" arterial, o que facilita a diálise de pacientes hipotensos; - a unidade dialisadora e todas as conexões vêm esterilizadas e prontas para uso. Desvantagens: - a existência de bomba rotatória no "set" arterial aumenta a hemólise no circuito extra-corpóreo; - a maior complexidade do manejo do aparelho, assim como a possibilidade de ocorrência de complicações mais graves, acarretam a neceessidade de um médico permanente na sala.

Kill - vantagens: - baixo custo operacional; - dispensa do uso de bomba para impulsionar o sangue devido a baixa resistência que oferece à circulação sangüínea; - dispensa da necessidade de preencher o aparelho com sangue, antes da hemodiálise, por possuir espaço interno pequeno; - técnica simplificada, podendo ser, após o início da diálise, manuseado pela própria enfermeira. Desvantagens: - tempo requerido para diálise, aproximadamente 12 horas; - tempo de preparo do aparelho muito longo; - ausência de bomba para impulsionar o sangue, o que o torna pouco eficaz para dialisar pacientes hipotensos.

\section{IV - O TRABALHO DA ENFERMEIRA}

A Unidade de Hemodiálise do Hospital das Clínicas da Facuídade de Medicina de Ribeirão Preto, está ligada à Unidade de Transplante Renal, sendo, portanto, nossos pacientes, de um modo geral, portadores de insuficiência renal crônica irreversível.

Os pacientes renais crônicos dependem para viver de diálises periódicas e sucessivas, o que implica em internações também periódicas e sucessivas por tempo indeterminado.

A enfermeira é o elemento que está em maior contacto com o paciente, estando presente antes, durante, e após a diálise. Ela deverá estar alerta para detectar possíveis intercorrências durante a diálise, e tomar as medidas cabíveis com presteza e rapidez, pois a vida do paciente pode depender de muitas destas providências.

Segundo HAMPERS e SCHUPAK, (4) pode ocorrer durante a diálise:

- hipotensão e choque, em geral devido a hipovolemia;

- parada cardíaca;

- frio e tremor, de modo geral, decorrente de reação piro- 
gênica causada por toxinas bacterianas, por contaminação do banho de diálise ou alteração da temperatura do banho;

- náuseas e vômitos. Embora estes sintomas sejam também encontrados em pacientes renais crônicos que não estejam em diálise, este processo pode predispor a tais sintomatologias devido à hipotensão, manifestações neurológicas (síndrome de desequilíbrio), e transtornos emocionais.

- sintomas cerebrais, que podem aparecer durante, no final, ou imediatamente após a hemodiálise. Estes sintomas podem variar desde agitações, contrações, confusões, até crises convulsivas. Estas manifestações aparecem, geralmente, quando se usa um dialisador eficaz, mas podem aparecer com qualquer tipo de dialisador, inclusive na diálise peritoneal. Não se conhece bem a causa desta disfunção, mas parece estar relacionada, pelo menos em parte, à diálise eficaz rápida. A maioria dos trabalhos experimentais indicam a queda brusca da uréia sérica, como principal causa das manifestações neurológicas. A diminuição do nível de uréia sanguínea ocorre mais rapidamente do que a diminuição do nível de uréia do líquido céfalo-raquidiano;

- coagulação do sangue no aparelho, decorrente de deficiência de heparinização;

- rompimento da membrana dialisadora o que produz uma hemorragia de intensidade variável, segundo sua duração e fluxo sangüíneo. Alguns aparelhos são providos com dispositivos especiais, que acusam a presença de hemoglobina no líquido de diálise. $\mathrm{Na}$ ausência deste monitor, é necessário uma vigilância da coloração do líquido, a intervalos regulares;

- problemas na cânula, tais como: diminuição do fluxo sangüíneo, (o que pode significar formação de coágulos no conjunto) e desconexão da mesma (o que pode causar hemorragia grave). O delivramento do "shunt", de modo geral, exige a presença do médico, pode ser um procedimento potencialmente perigoso, deviåo a possibilidade de uma embolia pulmonar. Em alguns serviços, este procedimento fica a cargo de enfermeiras especializadas.

\section{Cuidados de enfermagem}

Em nossa unidade, contamos com dois tipos de pacientes: os pacientes internados e os pacientes que só comparecem ao hospital na data pré-fixada, para se submeter à hemodiálise.

Os cuidados básicos de enfermagem, tanto para um como para outro, são, de maneira geral, os mesmos, diferindo apenas no que diz respeito a certas rotinas administrativas, e a orientações especiais que o paciente e sua família deverão receber. 
Os cuidados de enfermagem devem abranger não só os cuidados físicos, mas também os psicológicos e espirituais.

Quanto ao aspecto físico, a enfermeira atenderá as necessidades básicas do paciente, e dispensará todos os cuidados relativos ao paciente em diálise:

- pesar o paciente antes, e após a diálise para contrôle da quantidade de líquido perdido durante a mesma;

- colher sangue do paciente para tempo de coagulação de hora em hora;

- verificar os sinais vitais, antes do início da diálise, e periodicamente e cada 15 minutos, durante a $1 .{ }^{\text {a }}$ hora, e depois a cada hora;

- manter o paciente aquecido;

- observar o funcionamento do aparelho;

- tomar medidas cabíveis em caso de acidentes com o aparelho e a cânula do paciente;

- oferecer ao paciente a dieta prescrita, anotando sua aceitação. Em nosso serviço, os pacientes com insuficiência renal recebem uma dieta, hipoproteica (40 a 60g/dia), e hipossódica (400 a $1000 \mathrm{mg} /$ dia), com restrição de potássio e água;

- estar atenta às intercorrências que podem aparecer;

- chamar o médico sempre que julgar necessário;

- nunca deixar o paciente sozinho durante a hemodiálise;

- colher sangue do paciente antes e após a diálise, para contrôle das condições do paciente e eficiência da diálise. Os exames sangüíneos que são realizados, são de: uréia e creatinina, $\mathrm{Na}$ e $\mathrm{K}$, hematológico completo; micro-hematócrito, $\mathrm{pH}, \mathrm{pCO}_{2}$.

Existe, geralmente, uma dificuldade da aceitação, e na manutenção da dieta pelo paciente. Pode-se tentar contornar tal problema, fazendo-se um gráfico que relacione os níveis de uréia nitrogenada, potássio sangüíneo, e pressão arterial, com sua dieta. Isto ajuda a uma maior compreensão, e aceitação do regime alimentar pelo paciente.

Outro ponto que precisa ser focalizado é o cuidado diário que deverá ser dispensado ao local aonde estão inseridas as cânulas, a fim de reduzir a probalidade de infecção. Deve-se fazer uma limpeza e desinfecção da área ao redor da inserção, e protegê-la com um curativo fixado com atadura de crepe.

Os fatores psíquicos exercem uma grande influência $\mathrm{n}_{\mathrm{a}}$ reabilitação destes pacientes. Segundo L. Farré e R. Castellá,(1) existem três fases evolutivas, no plano emocional, durante o tratamento: de iniciação, de depressão, e de adaptação.

A fase de iniciação ocorre quando o paciente começa o trata- 
mento de hemodiálise, e caracteriza-se por um período de euforia e otimismo, pois o rim artificial surge como um meio de salvação.

A fase de depressão aparece após uma série de sessões de hemodiálises. O paciente tenta resistir ao fato de que sua única salvação consiste na hemodiálise ,e conscientiza-se da precariedade do seu estado.

A última fase é a da adaptação, quando o paciente resigna-se à sua sorte, adapta-se ao tratamento de hemodiálises periódicas, e passa a cultivar uma idéia obsessiva, que representa a volta à vida: - o transplante renal.

O bom êxito da hemodiálise prolongada depende, em grande parte, da relação paciente-enfermeira. o paciente é, na maioria das vezes, mantido vivo por uma máquina, vivendo, portanto, um estado de dependência. Sua tendência é de se apegar às pessoas que participam de seu cuidado, o que aumenta, progressivamente, sua necessidade delas. É necessário encorajar a independêcia destes pacientes, embora a enfermeira deva estar sempre de prontidão ao lado para deles orientá-los (FELLOWS2).

As famílias dos pacientes apresentam também problemas emocionais, por viverem constantemente em um estado de tensão e incerteza acerca do futuro.

Tanto os pacientes, quanto sua família, requerem uma assistência psicológica sistemática e efetiva.

A equipe de saúde que presta assistência aos pacientes renais crônicos participa constantemente dos seus problemas emocionais, criando laços afetivos, e sofrendo frustrações, principalmente, quando algum paciente vem a falecer.

Estas situações de "stress" alteram a estabilidade emocional da equipe, que também necessita de uma terapia de apoio, para que possa suportar, e transpor, de forma adequada, estes obstáculos.

A assistência espiritual exerce influência benéfica, na maioria dos pacientes e família, devendo, portanto, ser providenciada sempre que solicitada pelo paciente.

\section{CONCLUSÕES}

1. O cuidado do paciente em hemodiálise é uma área recente no campo da enfermagem. É necessário que a enfermagem se aprofunde, se aperfeiçoe, e se atualize constantemente nesta área.

2. O conhecimento da aparelhagem e seu funcionamento é de grande importância, para que se possa dar uma assistência efetiva ao paciente.

3. Para uma assistência de enfermagem eficiente, é necessário que a enfermeira responsável pelo serviço tenha conhecimentos es- 
pecializados sobre fisiologia renal, e insuficiência renal aguda e crônica. A falta de base teórica torna-la-á insegura no planejamento, e na execução dos cuidados de enfermagem.

4. A enfermeira a psicóloga e a dietista devem trabalhar em contacto permanente, em benefício do paciente.

5. O pessoal que irá trabalhar num serviço de hemodiálise deve ser rigorosamente selecionado, e devidamente treinado.

6. A assistência integral do paciente depende de um bom entrosamento entre os diversos departamentos e serviços hospitalares

\section{REFERENCIAS BIBLIOGRAFICAS}

1 - FARRE, L, \& CASTELLA, R. - Aspectos psicológicos en un programa de hemodiálisis periódicas. Anales de la Fundacion Puigvert, 4 (1): 84-98, enero, 1974.

2 - FELLOWS, B.J. - The role of nurse in a chronic dialysis unit. Nurs. Clin. North Am. 1 (4) : 577-586, Dec., 1966.

3 - FERRE, J. - Accesos vasculares para el riñon artificial: canulas e fistulas. Anales de la Fundacion Puigvert, 4 (1):21-30, enero, 1974.

4 - HAMPERS, C. L. \& SCHUPAK, E. -- La hemodiálisis prolongada, Barcelona, Ed. Científico-Médica, 1970.

5 - RIO, G. del - Riñon artificial - Anales de la Fundacion Puigvert, 4 (1) : 7-20, enero, 1974.

6 - SABBAGA, E, \& VASCONCELOS, E. - Insuficiência renal aguda. São Paulo, Savier, 1970.

\section{AnexoI}

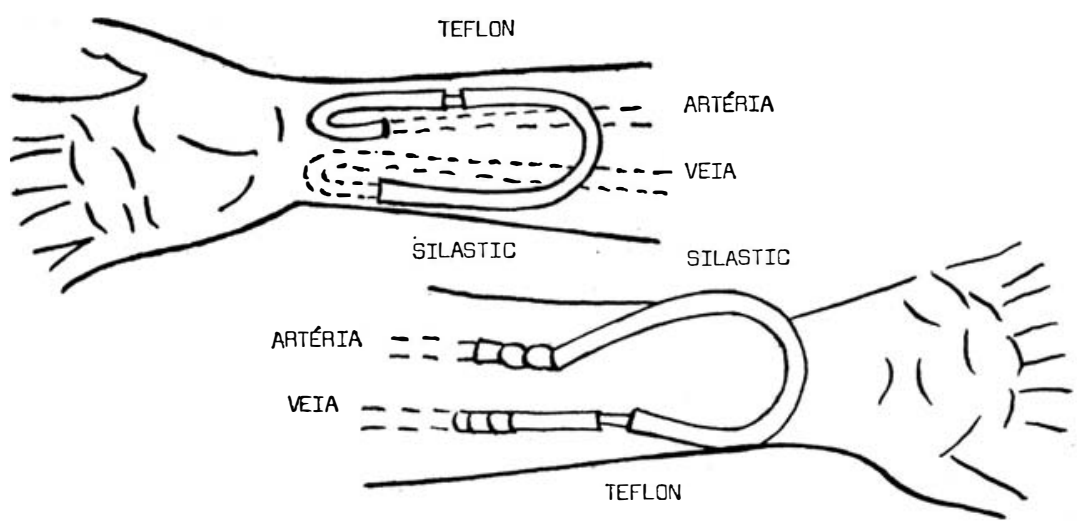




\section{ANEXO II}

\section{PROCEDIMENTO CORRETO PARA MANIPULAÇÃO DA CÂNULA}

- retira-se cuidadosamente a faixa crepe do curativo;

- limpa-se o braço, ou perna, e as inserções da cânula com sterylderme; se houver crostas em volta destas, retirá-las cuidadosamente com uma pinça;

- sob cada ramo da cânula, coloca-se uma gaze, dobrada ao meio, para proteção;

- antes de desconectar a cânula, para a colheita do material (sangue), e o início da hemodiálise, deve-se passar uma solução de mertiolate nos ramos, e proteger o braço ou perna do paciente com campos, compressas ou gazes esterilizadas, para que não haja contaminação dos ramos arterial e venoso da cânula;

- clampa-se os ramos, e desconecta-se o sistema, tomando-se cuidado para não tracionar a ponte arterio-venosa; colhe-se sangue para exames, encaminhando-o para o laboratório;

- hepariniza-se o paciente pelo ramo venoso, de acordo com a dose adequada.

\section{PROCEDIMENTO CORRETO PARA MANIPULAÇÃO DA FÍSTULA} ARTÉRIO-VENOSA

- retira-se o curativo, e faz-se assepsia da pele;

- injeta-se próximo ao local aonde se vai fazer a punção, 0,5 ml de xilocaína subcutâneo;

- punciona-se a veia e a artéria com 'Butterfly" n.o 16 ou 18, fixando-se bem;

- colhe-se o sangue que flui pelo "Butterfly" arterial para os exames, e hepariniza-se o paciente pelo ramo venoso. 